\title{
PREVALANCE OF OCULAR MORBIDITY AMONG SCHOOL CHILDREN OF PERUMKADAVILA BLOCK, THIRUVANANTHAPURAM, SOUTH KERALA
}

\author{
M. C. Vasantha Mallika ${ }^{1}$, Siva Sree Ranga M. $K^{2}$ \\ ${ }^{1}$ Associate Professor, Department of Community Medicine, Dr. SMCSI Medical College, Karakonam, Thiruvananthapuram, India. \\ ${ }^{2}$ Assistant Professor, Department of Anatomy, Dr. SMCSI Medical College, Karakonam, Thiruvananthapuram, India.
}

\section{ABSTRACT}

In spite of National Programme for Control of Blindness with its control strategies revised from time to time to provide comprehensive health care to the community, blindness and other conditions of ocular morbidity continue to be problems of much Public Health importance. Considering the fact that one-third of India's blind lose their eyesight before the age of 20 years and many of them are under fifteen years when they become blind, early detection and treatment of ocular morbidity among children is important. In Kerala, only some hospital based data are available based on the studies conducted in Regional Institute of Ophthalmology and Medical College Hospitals. Only piece meal data on field based studies are existing.

\section{OBJECTIVES}

1. To study the prevalence of ocular morbidity among school children of age group 9-15 years.

2. To find the socio demographic factors associated with ocular morbidity in children.

\section{METHODOLOGY}

Across sectional study was conducted among a sample of 3130 students of the age group 9-15 years from Government, Private and Aided schools of Perumkadavila Block Panchayat for three months from November 2013. Children were subjected to measurement of height and weight, general examination of the eyes, torch light examination of anterior segment and fundus examination, visual acuity for distant vision and for near vision. Colour blindness was checked using Ishihara's chart. Sociodemographic details were collected using the pretested Performa.

\section{RESULTS}

$28.9 \%$ of the study group was having one or more form of ocular morbidity. Majority of the children studied were of 12 years age. Most of the ocular morbidities were either preventable or curable. Among the children having ocular morbidity the leading cause was refractive error (17.9\%) followed by Vitamin A deficiency (9.6\%), Conjunctivitis (0.9\%), Blepharitis $(0.3 \%)$, Squint (0.1\%), Colour blindness $(0.1 \%)$ and Ptosis $(0.01 \%)$. The presence of ocular morbidity showed significant association with education, occupation and income of the parent.

\section{CONCLUSION}

The study was useful for detecting preventable and treatable causes of defective vision early in life and thus for minimizing longterm permanent visual disability.

\section{RECOMMENDATIONS}

The knowledge about the distribution and socio-demographic association of ocular morbidity would enable in planning of eye care services and to reduce visual impairment. As there is high prevalence of ocular morbidity among school children, it can be suggested that early screening programmes in primary schools can detect a good proportion of visual impairment and other ocular morbidities sufficiently early so that early interventions in such children will help in preventing the progression of the conditions which can lead to blindness.

\section{KEYWORDS}

Ocular Morbidity, Visual Acuity, Socio-demographic Factors.

HOW TO CITE THIS ARTICLE: Mallika MCV, Siva Sree Ranga MK. Prevalance of ocular morbidity among school children of Perumkadavila block, Thiruvananthapuram, South Kerala. J Evolution Med Dent Sci 2016;5(6):319-324, DOI: $10.14260 /$ jemds/2016/69

\section{INTRODUCTION \\ WHO defined blindness as "Visual acuity of less than 3/60} (Snellen) or its equivalent.

Financial or Other, Competing Interest: None.

Submission 16-12-2015, Peer Review 17-12-2015,

Acceptance 01-01-2016, Published 21-01-2016.

Corresponding Author:

Dr. M. C. Vasantha Mallika,

Siva Sri Sadanam, Vellarada-695505,

Thiruvananthapuram Dist.,

S. Kerala.

E-mail: dr.mcvasanthamallika@gmail.com

DOI: $10.14260 /$ jemds/2016/69
In 2010 among an estimated 285 million visually disabled people worldwide $90 \%$ were living in developing countries; about $80 \%$ of blindness was avoidable (Treatable or potentially preventable). ${ }^{1}$ Ocular morbidity leads to reduced economic and social status and it may also result in premature death. The major causes of ocular morbidity worldwide are glaucoma, accidents, diabetes, vascular disorders, cataract and degeneration of ocular tissues especially of retina and hereditary conditions. An estimated 19 million children are visually impaired. Out of this 12 million children are visually impaired due to refractory errors, a condition that could be easily diagnosed and corrected. 
The pattern of ocular diseases vary in different parts of the world and is influenced by racial, geographic, socioeconomic and cultural factors. ${ }^{2-6}$ Studies on ocular morbidity show conditions of conjunctiva, cornea, iris, lens, intraocular humor, retina and optic nerve, extraocular muscles and occipital centre of brain. Reasons of ocular morbidity may be congenital, traumatic, inflammatory, neoplastic, degenerative and miscellaneous conditions of these eyerelated structures. These result in varying levels of ocular morbidity, which can lead to partial or total blindness. The common ocular diseases worldwide are cataract, glaucoma, conjunctivitis, corneal ulcers, uveitis, refractive errors, vitamin A deficiency, pterygium and other diseases. ${ }^{7}$ Other eye diseases include trachoma, orbital diseases, retinitis pigmentosa, chalazion, pseudophakia/aphakia, diabetic retinopathy, congenital ptosis, optic neuropathy, strabismus, sixth cranial nerve paresis, staphyloma and choroidal melanoma, onchocerciasis and ocular malignancies.

In India according to a rapid national survey on the estimated prevalence of blindness 2006-07, estimated national prevalence of childhood blindness/low vision was 0.8 per $1000 .^{8}$ The major causes of blindness and low vision and their prevalence in India are cataract (62.6\%), uncorrected refractive errors in the form of myopia, hyperopia, astigmatism $(19.7 \%)$, glaucoma $(5.8 \%)$, posterior segment pathology $(4.7 \%)$, corneal opacity $(0.9 \%)$, other causes (4.19\%), surgical complications (1.2\%) and posterior capsular opacification $(0.9 \%) .{ }^{8}$ In India, as per 2006-07 survey. ${ }^{8}$ the prevalence of blindness was 1 percent. Visual impairment due to refractive errors is a condition that could be easily diagnosed and corrected. Of the children who are visually impaired due to refractive errors, more than $1.5 \%$ are irreversibly blind for the rest of their lives. ${ }^{9}$ In India, uncorrected refractive errors are responsible for about 19.7\% of blindness. ${ }^{9}$

In Kerala only some hospital-based data are available on ocular morbidity based on the studies conducted in Regional Institute of Ophthalmology and Medical College Hospitals. Field based data on the extent of the problem are not available. Only piece meal data are existing. It would be interesting and informative to do the study on school children (of age group 915 years) who represent a selective sample of the community. Being a captive population, children are the best group to study the prevalence of ocular morbidity, so that prevention of further progress of the conditions is possible in this population of the community.

In developing countries like India school eye screening should encompass common, but treatable and preventable ocular problems that could have immediate or long-term negative effect on the learning activities of the student. ${ }^{8}$ It has been found that ocular morbidity among school children of the age group $10-15$ years is $30-40 \%$. This affects their scholastic performance and extra-curricular activities. It has been estimated that $80-85 \%$ of the learning process is done via visual pathway. ${ }^{10}$

However, if parents and teachers of children who are blind or visually impaired do not understand the nature of visual disability and fail to provide appropriate compensatory learning options; the children's opportunities, experiences and development will be more restricted than necessary. ${ }^{11}$ Considering the fact that one-third of India's blind lose their eyesight before the age of 20 years and many of them are under fifteen years when they become blind, early detection and treatment of ocular morbidity among children is important. Children and adolescents comprise a major proportion of Indian population and are important as they are the future of country's development. ${ }^{12}$

In rural areas where a good proportion of people belonging to low socioeconomic group live, the prevalence of preventable and treatable causes of low vision is high. This high prevalence of ocular morbidity may a certain extent be due to under-utilization of available health infrastructure. Only a few children undergo regular and complete eye examinations.

Hence, the present study is an attempt to determine the prevalence of ocular morbidity among school children of the age group 9 to 15 years of a rural area of Thiruvananthapuram district in South India and to find out the socio-demographic factors related to ocular morbidity. This knowledge can be used for devising strategies based on the outcome of the study so that the problem of ocular morbidity in the community can be reduced.

\section{OBJECTIVES}

1. To study the prevalence of ocular morbidity among school children of age group 9-15 years.

2. To find the socio-demographic factors associated with ocular morbidity in children.

\section{METHODOLOGY \\ Study Design}

Cross sectional study.

\section{Study Area}

Perumkadavila Block Panchayat located 35 kilometers towards south from Thiruvananthapuram city, bounded on the north by Aryan code Grama Panchayat, south and east by Neyyattinkara Municipality and on the west by Kunnathukal Grama panchayat.

\section{Study Population}

Among the students from Government, Private and Aided schools of Perumkadavila Block Panchayat, a sample of study subjects maintaining proportion from them is selected of the age group 9-15 years. The Perumkadavila Block Panchayat is comprised of five Grama Panchayats. A total of 45 schools including Government, Private and Aided schools are there in this area.

\section{Sample Size}

Calculated using the formula $4 \mathrm{pq} / \mathrm{d} 2$.

Prevalence, $\mathrm{P}=11.2$.

$\mathrm{Q}=100-\mathrm{P}=88.8$.

Effect Size $=10 \%$ of $\mathrm{P}=1.12$.

Sample size $=(4 \times 11.2 \times 88.4) / 1.25=3125$.

The sample size is rounded to 3130 .

\section{Selection of Study Subjects}

Multistage random sampling method was used.

\section{Study Period}

Three months from November 2013.

Before starting the study, Ethics Committee clearance was obtained from the Institutional Ethics Committee. Informed consent was taken from the children. In the case of children below 12 years of age, informed consent was obtained from the parents and assent from the students. 


\section{Method of Data Collection}

The students of the study group were examined using a pretested performa. Screening of children was done with the help of Ophthalmic assistant from Dr. SM CSI Medical College, Karakonam. Sociodemographic details were collected. Socioeconomic status of children was assessed using modified Kuppuswamy's scale. Children were subjected to measurement of height and weight, general examination of the eyes, torch light examination of anterior segment and fundus examination with undilated pupil. Visual acuity for distant vision was assessed using Snellen's chart and for near vision using near vision test types; Colour blindness was checked using Ishihara's chart. Vitamin A deficiency was diagnosed if there is history of night blindness or on examination there were signs of conjunctival xerosis, Bitot's spots, corneal xerosis or keratomalacia. Measurement of Intraocular pressure were performed using tonometer. Cover-uncover test was done to detect manifest or latent squint. During examination, children were educated regarding prevention of ocular morbidity.

\section{Statistical Analysis}

Data were entered in Excel spread sheet. Statistical analysis was done with the help of computer package. Proportion with confidence interval was found out to estimate the prevalence of ocular morbidity. The results were tested by Pearson's Chisquare test with Yates correction wherever necessary.

\section{RESULTS}

In the cross-sectional study to assess the prevalence of ocular morbidity among school children, a total number of 3130 children were screened from the schools of Perumkadavila Panchayat. The data were analysed and tables and figures were constructed to describe the study population, to assess prevalence of ocular morbidity, to find out the relation of socio-demographic factors with ocular morbidity and to see the association of some selected variables with ocular morbidity.

\section{DESCRIPTION OF STUDY POPULATION}

\begin{tabular}{|c|c|}
\hline Study Participants (N=3130) & Number (Percentage) \\
\hline \multicolumn{2}{|l|}{ Age (Years) } \\
\hline 9 & $137(4.4 \%)$ \\
\hline 10 & $382(12.2 \%)$ \\
\hline 11 & $556(17.8 \%)$ \\
\hline 12 & $892(28.5 \%)$ \\
\hline 13 & $520(16.6 \%)$ \\
\hline 14 & $210(6.7 \%)$ \\
\hline 15 & $433(13.8 \%)$ \\
\hline \multicolumn{2}{|l|}{ Gender } \\
\hline Male & $1772(56.6 \%)$ \\
\hline Female & $1358(43.4 \%)$ \\
\hline \multicolumn{2}{|l|}{ Religion } \\
\hline Hindu & $2444(78.1 \%)$ \\
\hline Christian & $598(19.1 \%)$ \\
\hline Muslim & $88(2.8 \%)$ \\
\hline \multicolumn{2}{|l|}{ Education of Parent } \\
\hline Illiterate & $1236(39.5 \%)$ \\
\hline Primary school & $546(17.4 \%)$ \\
\hline Middle school & $302(9.6 \%)$ \\
\hline High school & $914(29.2 \%)$ \\
\hline Higher secondary & $100(3.2 \%)$ \\
\hline College/professional & $32(1 \%)$ \\
\hline
\end{tabular}

\begin{tabular}{|c|c|}
\hline Occupation of Parent & \\
\hline Unskilled worker & $638(20.4 \%)$ \\
\hline Semiskilled worker & $544(17.4 \%)$ \\
\hline Skilled worker & $1640(52.4 \%)$ \\
\hline Clerical/Shop & $250(8 \%)$ \\
\hline Professional & $58(1.9 \%)$ \\
\hline Income of Parent & $32(1.1 \%)$ \\
\hline APL & $3098(98.9 \%)$ \\
\hline BPL & Table 1: Description of study population \\
\hline
\end{tabular}

Majority of the children studied were of 12 years age. $56.6 \%$ were males and $43.4 \%$ were females. It is in contrary to the sex ratio of Kerala. It may be due to more dropouts among girls during the study period. Majority of children were Hindus (78.1\%) followed by Christians (19.1\%) and Muslims (2.8\%). Parents of $39.5 \%$ of the children were illiterate and only $1 \%$ were degree holders. Parents of most of the children were skilled workers (52\%) and unskilled (20\%). Most of the children belonged to poor socio-economic status.

\section{PREVALENCE OF OCULAR MORBIDITY}

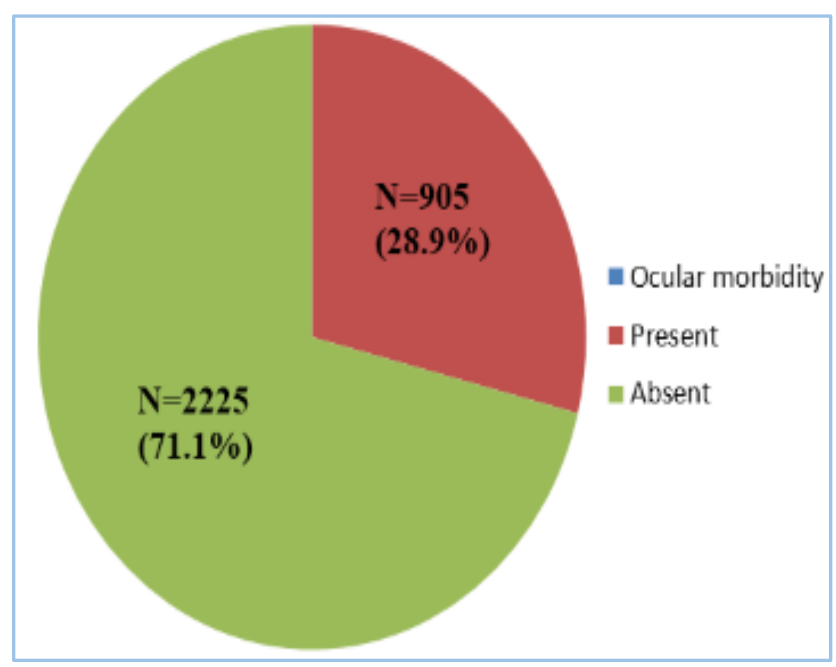

Fig. 1: Distribution of study group According to Ocular morbidity

$28.9 \%$ of the study group was having one or more form of ocular morbidity.

\begin{tabular}{|c|c|c|}
\hline Ocular Morbidity & Frequency & Percentage \\
\hline No Ocular Morbidity & 2225 & 71.1 \\
\hline Vitamin A deficiency & 301 & 9.6 \\
\hline Refractive error & 559 & 17.9 \\
\hline Conjunctivitis & 28 & 0.9 \\
\hline Colour Blindness & 4 & 0.1 \\
\hline Ptosis & 1 & 0.01 \\
\hline Squint & 3 & 0.1 \\
\hline Blepharitis & 9 & 0.3 \\
\hline Total & 3130 & 100 \\
\hline
\end{tabular}

In the present study, most of the ocular morbidities were either preventable or curable. Among the children having ocular morbidity, the leading cause is refractive error ( $17.9 \%$ ) followed by Vitamin A deficiency (9.6\%), Conjunctivitis $(0.9 \%)$, Blepharitis $(0.3 \%)$, Squint $(0.1 \%)$, Colour blindness $(0.1 \%)$ and Ptosis $(0.01 \%)$ respectively. 


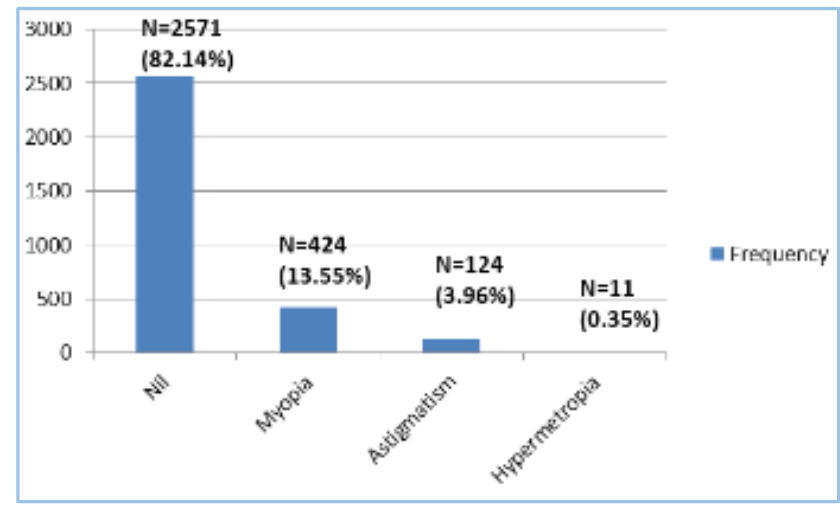

Fig. 2: Distribution according To type of Refractive error

\begin{tabular}{|c|c|c|c|}
\hline Age & \multicolumn{2}{|c|}{ Ocular Morbidity } & \multirow[t]{2}{*}{ Total } \\
\hline & $\begin{array}{c}\text { Present N } \\
(\%)\end{array}$ & $\begin{array}{l}\text { Absent } \\
\text { (N (\%) }\end{array}$ & \\
\hline 9 & $24(17.5)$ & $\begin{array}{c}113 \\
(82.5)\end{array}$ & 137 \\
\hline 10 & $78(20)$ & $304(80)$ & 382 \\
\hline 11 & $128(23)$ & $428(77)$ & 556 \\
\hline 12 & $328(36.8)$ & $\begin{array}{c}564 \\
(64.2) \\
\end{array}$ & 892 \\
\hline 13 & $236(45.4)$ & $\begin{array}{c}284 \\
(54.6)\end{array}$ & 520 \\
\hline 14 & 37 (17.6) & $\begin{array}{c}173 \\
(82.4)\end{array}$ & 210 \\
\hline 15 & $74(17.1)$ & $\begin{array}{c}359 \\
(82.9) \\
\end{array}$ & 433 \\
\hline Total & 905 & 2225 & 3130 \\
\hline$\chi 2=957.33$ & \multicolumn{2}{|c|}{ df 12} & $\begin{array}{c}P \\
<0.001\end{array}$ \\
\hline \multicolumn{4}{|l|}{ Gender } \\
\hline Male & $582(48.9)$ & $\begin{array}{c}1190 \\
(51.1) \\
\end{array}$ & 1772 \\
\hline Female & $323(31.2)$ & $\begin{array}{l}1035 \\
(68.8)\end{array}$ & 1358 \\
\hline Total & 905 & 2225 & 3130 \\
\hline$\chi 2=81.350$ & \multicolumn{2}{|c|}{ df 7} & $\begin{array}{c}P \\
<0.001 \\
\end{array}$ \\
\hline \multicolumn{4}{|l|}{ Religion } \\
\hline Hindu & $674(27.6)$ & $\begin{array}{l}1770 \\
(72.4)\end{array}$ & 2444 \\
\hline Christian & $229(38.3)$ & $\begin{array}{c}369 \\
(61.7)\end{array}$ & 598 \\
\hline Muslim & $2(2.3)$ & $86(97.7)$ & 885 \\
\hline Total & 905 & 2225 & 3130 \\
\hline$\chi^{2}=162.239$ & \multicolumn{2}{|c|}{ df 14} & $\begin{array}{c}P \\
<0.001 \\
\end{array}$ \\
\hline \multicolumn{4}{|l|}{$\begin{array}{c}\text { Occupation of } \\
\text { Parent }\end{array}$} \\
\hline Unskilled & $399(62.5)$ & $\begin{array}{c}239 \\
(37.5)\end{array}$ & 637 \\
\hline Semi-skilled & $166(30.5)$ & $\begin{array}{c}378 \\
(69.5)\end{array}$ & 544 \\
\hline Skilled & $269(16.4)$ & $\begin{array}{c}1371 \\
(83.6)\end{array}$ & 1640 \\
\hline Clerical/Shop & $43(17.2)$ & $\begin{array}{c}207 \\
(82.8) \\
\end{array}$ & 250 \\
\hline Professional & $28(48.2)$ & $30(51.7)$ & 58 \\
\hline Total & 905 & 2225 & 3130 \\
\hline$\chi^{2}=631.023$ & \multicolumn{2}{|c|}{ df10 } & $\begin{array}{c}P \\
<0.001\end{array}$ \\
\hline
\end{tabular}

\begin{tabular}{|c|c|c|c|}
\hline $\begin{array}{l}\text { Education of } \\
\text { Parent }\end{array}$ & & & \\
\hline Illiterate & 644 (52.1) & $\begin{array}{c}592 \\
(47.9)\end{array}$ & 1236 \\
\hline Preschool & $161(29.5)$ & $\begin{array}{c}385 \\
(70.5)\end{array}$ & 546 \\
\hline Middle school & $32(10.6)$ & $\begin{array}{c}270 \\
(89.4)\end{array}$ & 302 \\
\hline High school & 34 (3.7) & $\begin{array}{c}880 \\
(96.3)\end{array}$ & 914 \\
\hline $\begin{array}{c}\text { Higher } \\
\text { secondary/PDC }\end{array}$ & $18(18)$ & $82(82)$ & 100 \\
\hline Degree & $16(50)$ & $16(50)$ & 32 \\
\hline Total & 905 & 2225 & 3130 \\
\hline$\chi^{2}=1678.427$ & \multicolumn{2}{|c|}{ df10 } & $\begin{array}{c}P \\
0.001\end{array}$ \\
\hline \multicolumn{4}{|c|}{$\begin{array}{l}\text { Table 3: Prevalence of ocular morbidity } \\
\text { in relation to socio-demographic factors }\end{array}$} \\
\hline
\end{tabular}

The prevalence of ocular morbidity was more among low socio-economic group. Presence of ocular morbidity showed significant association with education, occupation and income of parent. Some selected variables like poor nutritional status of children $(\chi 2=311.357$, df $14, \mathrm{P}<0.001)$, poor reading posture $(\chi 2=407.397$, df $7, P<0.001)$ and family history of ocular morbidity $(\chi 2=2583.95$, df $21, P<0.001)$ showed significant association with ocular morbidity.

\section{DISCUSSION}

The pattern of ocular morbidity may vary in different parts of the world and is influenced by racial, geographic socioeconomic and cultural factors. ${ }^{3-7}$ The prevalence of ocular morbidity was $28.9 \%$ in the present study. It is comparable to a study by Rajesh Kumar et al. (24.6\%) from Delhi. ${ }^{11}$ Jayanth D and Malathi K (27.65\%) from rural Maharashtra. ${ }^{12}$ and Madhu Gupta and others (31.6\%) from Shimla. ${ }^{13}$ In a study by Chaturvedi et al. prevalence of ocular morbidity was more than $40 \%$ in rural Delhi. ${ }^{14}$ and Kalikivayi et al. (43.5\%) at Hyderabad. ${ }^{15}$ Least prevalence of $11 \%$ was reported from Nepal; prevalance of $13 \%$ was reported by Prajapati P et al. among adolescents of Gandhinagar district. ${ }^{2}$ prevalence of ocular morbidity among school children of age 5-16 years (13.3\%) was reported by Amol Bansal. ${ }^{16}$ et al from Kolar District, South India and $15.6 \%$ by Wedner SH et al. in rural Tanzania. ${ }^{17}$ The common ocular diseases. ${ }^{18}$ worldwide are cataract, glaucoma, conjunctivitis, corneal ulcers, uveitis, refractive errors, Vitamin A deficiency, pterygium. Other eye diseases include trachoma, onchocerciasis, xerophthalmia and ocular malignancies.

Refractive errors (17.9\%) were the most common ocular morbidity in the present study. Most of the other studies done are on prevalence of refractive errors. Out of the total ocular morbidity, refractive errors constituted $89.6 \%$ in a study by Amol Bansal. ${ }^{16}$ et al. at Kolar District, South India.

Madhu Gupta et al. ${ }^{13}$ at Shimla and S Mahapatro et al. at Bhubanesar. ${ }^{19}$ had identified refractive error as the commonest morbidity among children (22\%). Prajapati et al. also had observed it as the commonest with a prevalence of $40.1 \%$ in their study at Gandhinagar. ${ }^{2}$ Prevalence of refractive error of $32 \%$ has been reported by Kalikivayi in a study from South India. ${ }^{15}$ and $61 \%$ among children in rural population of India by Dandona $\mathrm{R}$ et al.20 In a study at Pune among adolescent school children Col A Datta et al. noted $21.19 \%$ of refractive error. ${ }^{21}$ In the present study, $13.55 \%$ of the children 
were having Myopia, 3.96\% had Astigmatism and $0.35 \%$ had Hypermetropia. In a study by Amol Bansal.20 96\% of all refractive errors were myopes and $4 \%$ were hyperopes.

Uncorrected refractive error $(2.9 \%)$ was found to be an important finding among the children in the present study comparable (5.6\%) to the study by Jayant $\mathrm{D}$ and Malathi $\mathrm{K}$ in rural Maharashtra. ${ }^{14}$

In the present study, the prevalence of Vitamin A deficiency was 9.6 percent. In a study at rural North Maharashtra by Jayant D and Malathi, 25.58\% Vitamin A deficiency was reported.12 and $29.3 \%$ was noted by Prajapati et al. at Gandhinagar. ${ }^{2}$ Mausami Basu et al. reported $11.83 \%$ of conjunctival xerosis among students at Surat.22 and Bhattacharya et al. observed $8.16 \%$ Vitamin A deficiency among primary school students in Darjeeling district. ${ }^{23}$ but $\mathrm{S}$. Mahapatro et al. noted least prevalence of $2.25 \%$ Vitamin A deficiency in Bhubanesar. ${ }^{19} \mathrm{~A}$ high prevalence of vitamin A deficiency among school children aged 8-13 years have been reported in 1993 by Singh et al. ${ }^{24}$ Vitamin A deficiency was the commonest morbidity (33.8\%) in a study done in Karnataka. 25

Prevalence of conjunctivitis was $0.9 \%$ in our study. Jayant D and Malathi K reported a prevalence of $(2.57 \%)$ at rural Maharashtra. ${ }^{12}$ Madhu Gupta et al. (0.8\%) in Shimla,13 and by Prajapati (3.8\%) et al. at Gandhinagar. ${ }^{2}$ and Kumar R et al. (4.6\%) in urban and rural Delhi. ${ }^{11}$ High prevalence may be due to the poor personal hygiene. Higher prevalence of conjunctivitis and blepharitis (1.5-17.5\%) has been reported in other parts of India. $26-28$

In the present study, $0.1 \%$ had squint. Prevalence of squint has been reported from Haryana, Rajasthan, West Bengal and Delhi. ${ }^{14,26}$

The prevalence of ocular morbidity was more among low socio-economic group. Presence of ocular morbidity showed significant association with education, occupation and income of parent. Poor nutritional status of children, Poor reading posture and family history of ocular morbidity from studies done by medical students from south India showed significant association with ocular morbidity comparable to present study.

\section{SUMMARY AND CONCLUSION}

A cross-sectional study on the prevalence of ocular morbidity among school children of rural Kerala, South India was done during a period of three months from November 2013 with the objectives 1 . To study the prevalence of ocular morbidity among school children of the age group 9-15 years of Perumkadavila panchayat and 2. To study the association of socio-demographic factors of children with ocular morbidity.

The study group included 3130 children from schools selected by multistage sampling technique. Data were collected using pretested performa. Ocular morbidity included external examination of the eye, assessment of visual acuity, test for colour vision and squint. Out of total number of children studied $56.6 \%$ were males and $43.4 \%$ were females.

Among the children having ocular morbidity the leading cause was refractive error $(17.9 \%)$ followed by Vitamin A deficiency $(9.6 \%)$, Conjunctivitis $(0.9 \%)$, Blepharitis $(0.3 \%)$, Squint $(0.1 \%)$, Colour blindness $(0.1 \%)$ and Ptosis $(0.01 \%)$. Among children having refractive error, most of them were myopic. The prevalence of ocular morbidity was more in children of low socio-economic group. The presence of ocular morbidity showed significant association with education, occupation and income of the parent. Some selected variables like nutritional status of children and complaint of diminished vision were associated significantly with ocular morbidity. Uncorrected refractive errors were $2.9 \%$. Also family history of defective vision and habits like reading posture showed significant association with myopia in children.

Among the children studied, three of them had congenital colour blindness. The study could serve as useful purpose for detecting correctable causes of defective vision early in life and thus minimizing long term permanent visual disability. All the children were given health education regarding ocular hygiene, consumption of nutritious food including green leafy vegetables and importance of observing right reading posture. All the children found to be having refractive error were provided with spectacles corrected to visual acuity $6 / 6$.

\section{RECOMMENDATIONS}

The knowledge about the distribution and demographic association of ocular morbidity would enable in planning of eye care services to reduce visual impairment caused by them. As there is high prevalence of ocular morbidity among school children, it can be suggested that early screening programmes in primary schools can detect a good proportion of visual impairment and other ocular morbidities sufficiently early so that early interventions in such children will help in preventing the progression of the conditions, which can lead to blindness.

\section{ACKNOWLEDGEMENTS}

We would like to thank the heads of the institutions, the teachers and the students for having been very cooperative in the collection of the data. We thank our entire department faculty and the parent institution for being encouraging and supportive throughout this study.

\section{REFERENCES}

1. WHO (2013), Visual impairment and blindness fact sheet, No. 282, June 2013.

2. Prajapati P, Oza J, Prajapati J, et al. Online J Health Allied Scs 2010, 9, 5.

3. Edema OT, Okojie OH. Pattern of eye diseases in Benin City, Nigeria. Afr J Med Pract 1997;4:86-90.

4. Mahmoud AO, Olatunji FO, Buari SB. Survey of blindness and ocular morbidities in Kwara State, Nigeria. Nig J Surg Sci 2005;15:26-30.

5. Rizyal A, Shakya S, Shresta RK, et al. A study of ocular morbidity of patients attending a satellite clinic in Bhaktapur, Nepal. Nepal Med Coll J 2010;12(2):87-89. [PubMed].

6. Ogwurike SC. Ocular diseases at Lere local government outreach post in Kaduna State of Northern Nigeria. WAJM 2007;26(1):20-23. [PubMed].

7. Carol C Prendergast. Issues of growth and development for blind and visually impaired children. In: Albert DM and Jackobiec eds. Principles and Practice of Ophthalmology, Chapter 401:2000; WB Saunders Company.

8. Govt. of India (2014), Annual Report 2013-14, Ministry of Health and Family Welfare, New Delhi.

9. Govt. of India (2012), Annual Report 2011-12, Ministry of Health and Family Welfare, New Delhi. 
10. Lippman 0 . Eye screening. Arch Ophthalmol 1962;68:692-802.

11. Kumar R, Dabas P, Mehra M, et al. Health and populationperspective and issues 2007;30:222-229.

12. Deshpande Jayant D, Malathi K. National Journal of Community Medicine 2011;2:249-254.

13. Gupta M, Gupta BP, Chauhan A. et al. Indian Journal of Ophthalmol 2009;57:133-138.

14. Chaturvedi S, Aggarwal OP. Asia Pac J Public Health 1999;11:30-33.

15. Kalikivayi V, Naduvilath TJ, Bansal AK, et al. Indian J Ophthalmol 1997;45:129-134.

16. Amol Bansal, Kanthamani Krishnappa, Narendra P Datti, et al. Ocular morbidity in school going children of Kolar District, South India. J Clin Biomed Sci 2012;2(4)

17. Wedner SH, Ross DA, Balire R, et al. Br J Ophthalmol 2000;84:1291-1297.

18. World Health Organisation. International Agency for Prevention of Blindness 2005 State of world sight vision 2020: the right to sight 1999-2005.

19. Mahapatro S, Das MK, Padhy GK, et al. Journal of Community Medicine 2010, 6.

20. Dandona R, Dandona L, Srinivas $M$, et al. Invest Ophthalmol Vis Sci 2002;43:615-622.
21. Datta A, Bhardwaj L, Patrikar SR, et al. Study of disorders of visual acuity among adolescent school children in Pune. MJAFI 2009;65:26-29.

22. Basu M, Das P, Pal R, et al. Indian J Ophthalmol 2011;59:475-479.

23. Bhattacharya RN, Shrivastava P, Sadhukhan SK, et al. Indian J Pub Health 2004;48:171-180.

24. F Singh MC, Gangane N, Murthy GVS. Evaluation of vitamin A status by conjunctival impression cytology among school children. Ind Paed 1993;30:1085-9.

25. BT Prasanna Kamath, BS Guru Prasad, R Deepthi, et al. Prevalence of ocular morbidity among school going children (6-15years) in rural area of Karnataka, South India. Int J Pharm Biomed Res 2012;3(4):209-212.

26. Desai S, Desai R, Desai NC, et al. School eye health appraisal. Indian J Ophthalmol 1989;37:73-75.

27. Pratap VB, Lal HB. Pattern of paediatric ocular problems in North India. Indian J Ophthalmol 1989;37:171-72.

28. Robinson B, Acron CJ, Millar CC, et al. The prevalence of selected ocular diseases and conditions. Optom Vis Sci 1997;74:79-91. 